\title{
Open Common Bile Duct Exploration in a Nigerian Tertiary Hospital
}

Adewale Adisa, Olusegun Alatise, Olalekan Olasehinde, Bolanle Ibitoye, Olukayode Arowolo, Oladejo Lawal

\author{
Obafemi Awolowo University Teaching Hospitals Complex, Ile-Ife, Nigeria
}

Correspondence to: Dr Adewale O. Adisa. Department of Surgery, Obafemi Awolowo University, Ile-Ife, 220005, Osun State, Nigeria. E-mail: wadisc@yahoo.com

\begin{abstract}
Background: The prevalence of extra-hepatic biliary stones in Nigeria is unknown and its treatment frequently undocumented. We have observed an increase in bile duct exploration in our hospital.
\end{abstract} Methods: This is an eight-year retrospective report on consecutive patients who underwent common bile duct exploration. The diagnosis, pre-operative preparation, intra-operative findings and post-operative outcome were documented. Results: Forty-one patients were explored; 33 females (80.5\%) and 8 (19.5\%) males. Four had sickle cell anaemia. Pre-operative ultrasound showed common duct dilatation in $36(87.8 \%)$, and choledocholithiasis in $29(70.7 \%)$. Six patients did abdominal CT, 2 MRCP and none ERCP. Choledocholithiasis was operatively confirmed in 39 (95.1\%) and dilated CBD without stones in 2.
T-tube was inserted in $17(41.5 \%)$ and primary closure of the common duct was done in 24 (58.5\%). The mean duration of operation (102 vs 184 minutes) and hospital stay (10.6 vs 14.4 days) were less with primary closure. Conclusion: Common bile duct exploration is increasingly being performed in our center with a good outcome. There is increasing adoption of primary closure of the common bile duct in our setting.

Key words: Common bile duct, T- tube

Ann Afr Surg. 2018; 15(2):62-67

DOI: http://dx.doi.org/10.4314/aas.v15i2.6

(C) 2018 Author. This work is licensed under the

Creative Commons Attribution 4.0 International

License.

Conflicts of Interest: None

Funding: None

\section{Introduction}

The prevalence of gallstone disease would appear low in Nigeria; population based studies are lacking though. Some reports of peculiar patient cohorts have reported $3 \%$ in pregnant Nigerian women (1), $17 \%$ in Nigerians with type 2 diabetes mellitus (2) and up to $24 \%$ among patients with sickle cell diseases (3). Presentation of choledocholithiasis and its treatment is scantily documented in Nigeria however, studies reporting on treatment and outcome of obstructive jaundice have highlighted varying prevalence of choledocholithiasis among different subsets of patients across Nigeria $(4,5)$. Current recommended treatment of common bile duct stones include endoscopic extraction with endoscopic retrograde cholangio-pancreatography (ERCP) as well as laparoscopic or open duct exploration and stone retrieval (6). Recent studies have affirmed the comparability of stone clearance with laparoscopic exploration compared to preoperative, intraoperative or postoperative ERCP $(7,8)$ Open exploration is now reserved for the difficult or failed endoscopic extraction and conversions during laparoscopic attempts. In our hospital, ERCP is not yet routinely performed and the laparoscopic approach is yet to be reported in any center in Nigeria with open retrieval being the most commonly adopted treatment for common bile duct stones. This study was carried out in two general surgery units of the Obafemi Awolowo University Teaching Hospitals Complex, Ile-Ife, Nigeria to review the indications, procedures and outcome of common bile duct exploration in patients presenting with choledocholithiasis in our hospital with the aim of highlighting temporal changes in the practice. 


\section{Methods}

All patients who underwent common bile duct exploration for choledocholithiasis at the Ife Hospital Unit of the Obafemi Awolowo University Teaching Hospitals Complex, (OAUTHC), Ile-Ife, Nigeria, from January 2009 through December, 2016 were the subjects of this study. All procedures were performed by consultant general adopting similar techniques as previously described (9). The operation register was used to retrieve patients' hospital numbers and their case notes were then reviewed for patient's characteristics, preoperative radiological and biochemical reports as well as detailed preoperative work-up. Intraoperative findings, perioperative and postoperative events were similarly reviewed and extracted into a proforma. Patients were grouped into two: those who had their procedures performed between 2009 and 2011 and those who were operated from 2012 onwards reflecting the period when cholecystectomy rate rose significantly in our hospital following consistent deployment of laparoscopic cholecystectomy(10). Data generated were subjected to descriptive analysis using IBM SPSS Version 22 for Windows.

\section{Results}

There were 41 patients over the study period including $8(19.5 \%)$ males and 33 females (80.5\%). Their ages ranged from 24 to 80 years with a mean of 47.16years $(\mathrm{SD}=16.45)$. Six patients $(14.6 \%)$ had no jaundice at initial presentation with right hypochondrial pain being their chief complaint, while duration of jaundice prior to presentation among the jaundiced patients ranged from one to 28 months with a median of 6 months. Four $(9.8 \%)$ patients were known sickle cell anaemia patients referred from the Haematology unit. The frequency of common bile duct exploration steadily increased over time from two patients yearly in 2009 and 2010 to seven cases in 2016 representing more than $200 \%$ increase. This corresponded to similar upsurge in the number of cholecystectomies performed in our center which rose from 13 in 2009 to 18 in 2012 and 30 in 2016.

Preoperative ultrasound (USS) diagnosis was cholelithiasis with choledocholithiasis in $29(70.7 \%)$ patients, carcinoma head of pancreas in $7(17.1 \%)$ patients, cholelithiasis with or without cholecystitis in 3 $(7.3 \%)$ and suspected cholangiocarcinoma in $2(4.9 \%)$.

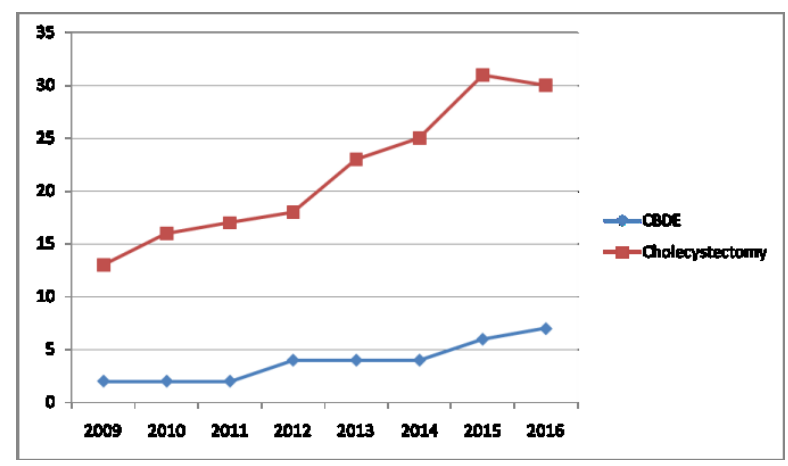

Figure 1: Upward trend of exploration and cholecystectomies

The common bile duct was reported to be dilated in 36 (87.8\%) patients and normal in the remaining five. In those with dilatation, the diameter estimated on USS ranged from 11 to $26 \mathrm{~mm}$ with a median $17 \mathrm{~mm}$. There was associated intrahepatic ductal dilatation in 11 patients. Six patients (14.6\%) had CT scan in addition to the USS. The findings of enlarged head of pancreas on $\mathrm{CT}$ in two of them reinforced a preoperative diagnosis of carcinoma head of pancreas. Two patients had Magnetic Resonance Cholangio-Pancreatography (MRCP) done at another center before being referred to us. None of the patients in this series had ERCP done preoperatively or postoperatively.

Serum bilirubin was elevated in $36(87.8 \%)$ patients (including one who had no clinically detectable jaundice) with predominant conjugated hyperbilirubinaemia in all of them. Preoperative total bilirubin ranged from 28 to $446 \mathrm{mmol} / \mathrm{L}$ while conjugated bilirubin ranged from 8 to $412 \mathrm{mmol} / \mathrm{L}$. Nine patients including the four known sickle cell anaemia (HbSS) patients presented with anaemia necessitating preoperative blood transfusion. Blood clotting profile was deranged in eleven patients with preoperative transfusion of fresh frozen plasma (FFP) in nine patients. Intraoperatively, choledocholithiasis was confirmed in thirty nine patients and dilated CBD with no stones in two others as shown in Table 1.

No concomitant malignant condition was recorded in this cohort of patients. Thirty-nine patients had cholecystectomy and common bile duct exploration (CBDE) while one had previous cholecystectomy before developing jaundice and another presented with 
recurrent stones after previous CBDE. The CBD was recorded to be dilated in all but two patients but the estimated dimensions were documented in only 28

Table 1: Findings and techniques in patients undergoing open common bile duct exploration

\begin{tabular}{|c|c|c|}
\hline \multicolumn{3}{|l|}{$\begin{array}{l}\text { Laboratory } \\
\text { Findings }\end{array}$} \\
\hline & $\begin{array}{c}\text { Conjugated } \\
\text { Hyperbilirubinaemia } \\
36(87.8 \%)\end{array}$ & $\begin{array}{c}\text { Normal } \\
\text { Bilirubin } \\
5(12.2 \%)\end{array}$ \\
\hline & $\begin{array}{l}\text { Anaemia } \\
9(22.0 \%)\end{array}$ & $\begin{array}{c}\text { Normal } \\
\text { Hemotocrit } \\
\text { level } \\
32(78.0 \%)\end{array}$ \\
\hline \multicolumn{3}{|l|}{$\begin{array}{l}\text { USS } \\
\text { Findings }\end{array}$} \\
\hline & $\begin{array}{c}\text { Choledocholithiasis } \\
29(70.7 \%)\end{array}$ & $\begin{array}{c}\text { Other } \\
\text { Diagnoses } \\
12(19.3 \%)\end{array}$ \\
\hline & $\begin{array}{c}\text { CBD dilatation } \\
36(87.8 \%)\end{array}$ & $\begin{array}{c}\text { Normal CBD } \\
5(12.2 \%)\end{array}$ \\
\hline \multicolumn{3}{|l|}{$\begin{array}{l}\text { Operative } \\
\text { findings }\end{array}$} \\
\hline & $\begin{array}{c}\text { CBD dilatation } \\
39(95.1 \%)\end{array}$ & $\begin{array}{c}\text { Normal CBD } \\
2(4.9 \%)\end{array}$ \\
\hline & $\begin{array}{c}\text { CBD Stones found } \\
39(95.1 \%)\end{array}$ & $\begin{array}{c}\text { No CBD } \\
\text { stones } \\
2(4.9 \%)\end{array}$ \\
\hline \multicolumn{3}{|l|}{$\begin{array}{l}\text { Closure after } \\
\text { CBDE }\end{array}$} \\
\hline & $\begin{array}{c}\text { T-tube insertion } \\
17(41.5 \%)\end{array}$ & $\begin{array}{c}\text { Primary } \\
\text { Closure } \\
24(58.5 \%)\end{array}$ \\
\hline
\end{tabular}

procedures with a range of 9-30mm. Location of stones was not documented in the majority of patients except in 14 instances where the supra-pancreatic portion of the CBD was the location in 10 of 14 . Number of stones extracted from the CBD ranged from one to six with a median of two stones. T-tube was inserted after CBD exploration in $17(41.5 \%)$ patients while primary closure was performed in $24(58.5 \%)$ patients. Primary closure was first performed in 2011 in our hospital and since then has risen from being performed in none before 2011 to being adopted in 24 of 35 (68.6\%) patients in the period following 2012 as depicted in Figure 2.

The mean duration of operation for all patients was 162 minutes $(\mathrm{SD}=59.10)$ with a range of $65-330$ minutes. This was considerably less $($ Mean $=102$; range 65 240minutes) when primary closure was performed compared to when T-tube was inserted (Mean 184; range 90-330minutes). This difference was statistically

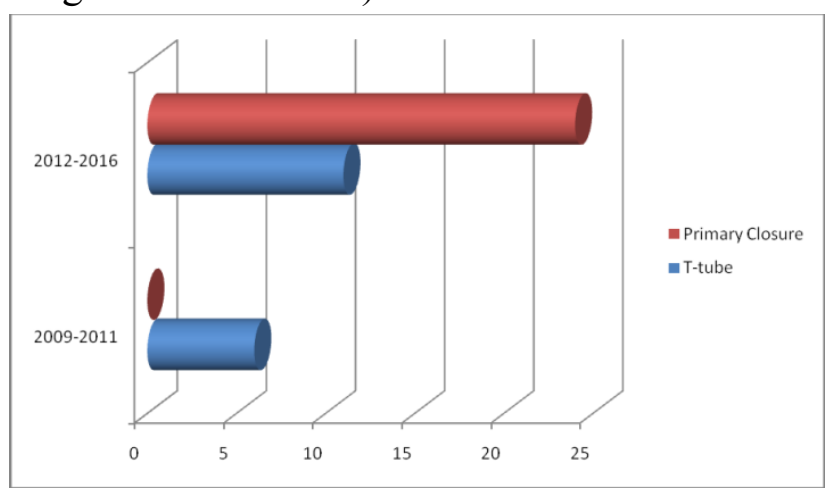

Figure 2: Increasing adoption of primary closure following common bile duct exploration from 2012-2016

significant, $(\mathrm{p}=0.02)$. Estimated blood loss ranged from $50 \mathrm{ml}$ to $1200 \mathrm{ml}$. Two patients had FFP transfused intraoperatively, two had both blood and FFP transfused while eight others had whole blood transfusion. Postoperatively, 14 of 17 patients with T-tube insertion had T-tube cholangiography done with findings of free flow of contrast in all cases. Postoperative length of stay ranged from 5-29 days, with a mean duration of 14.4 days when T-tube was inserted compared to 10.6 days when T-tube was avoided. This difference was not statistically significant, $p=0.532$. No mortality was recorded in this series. Median follow up duration was 11 months in this cohort. A patient who had primary closure presented 21 months after initial operation with recurrent right hypochondrial pain without jaundice. She had re-exploration and retrieval of retained stones and has been followed up for a year.

\section{Discussion}

The findings of this study have shown an increased trend towards primary closure of the CBD following its exploration in our center. The traditional method of always inserting a T-tube was practiced for several years before the period of this study and is still a routine with a few surgeons. In some instances, some surgeons adopt inappropriate sized T-tube for the varying degrees of dilatations of the CBD or outright improvisation with non-T tubes (usually small sized Foley's catheter) for stenting the duct. This is due to the long held belief of numerous benefits of insertion of T-tube for stenting of the CBD after exploration and its usefulness in 
investigating and intervening in subsequent challenges with the duct in the postoperative period. Many authors have however reported different problems arising from T-tube insertion including: prolonged duration of operation and length of hospital stay, increased incidence of positive bile culture, biliary peritonitis and wound infection, increased cost, tube dislodgement and migration as well as long term complications including bile duct stricture and recurrent CBD stones.(11-14) On the other hand, primary closure itself can be associated with a higher rate of retained stones particularly when intraoperative cholangiography is not employed. While there are not many randomized controlled trials with sound methodologies comparing the use of T-tube to primary closure following open CBD exploration, Gurusamy KS et al have conducted two systematic reviews on the subject on the Cochrane Database in 2007 and 2013.(15,16) In the first study, they reported longer hospital stay in the T-tube group but no statistically significant difference in other outcomes and concluded that primary closure is as safe as the use of T-tube. The 2013 study included more patients and employed more analyses and the authors' conclusion was that there is no justification for the use of T-tube except in the setting of an RCT. With advancement of the minimal access technique, there was a more rapid embrace of primary closure by many surgeons performing laparoscopic CBD exploration.(17-1)A recent systematic review with meta-analysis of sixteen RCTs with a total of 1770 patients undergoing laparoscopic CBD exploration with or without T-tube drainage found significantly better outcome in primary duct closure compared to T-tube drainage in terms of postoperative biliary peritonitis, operating time, postoperative hospital stay and median hospital expenses.(19) In our setting however, many surgeons still use T-tubes routinely due to the lack of interventional techniques such as ERCP for postoperative events.

The rising cases of CBD exploration we have performed over the period reflect the increasing number of cholecystectomies we performed as we received referrals for gallstones and other hepatobiliary condition due to consistent deployment of laparoscopic procedures in our unit. A number of the patients we reviewed in this study were primarily referred for laparoscopic cholecystectomy but had choledocholithiasis detected on preoperative evaluation. We commonly employ transabdominal ultrasound for preoperative evaluation in our center and only a few patients had MRCP done preoperatively. While a number of studies $(20,21)$ have affirmed the superiority of MRCP and endoscopic ultrasound for the detection of CBD stones, the cost and availability of these techniques in our setting has limited us to transabdominal ultrasound in most instances. In this study, detection rate of CBD stones with transabdominal USS was $70 \%$ with a number of patients only detected intraoperatively. Perhaps the consistent use of a team led by a consultant radiologist for evaluation of the biliary tree yielded the fairly high detection rate of CBD stones on USS in this series.

The importance of the ERCP for the diagnosis and treatment of many hepatobiliary conditions including choledocholithiasis in our setting and its nonavailability has been a recurring concern among Nigerian surgeons and physician gastroeneterologists. The American Society of Gastrointestinal Endoscopy (ASGE) affirmed that endoscopic sphincterotomy and extraction of stones is successful in more than $90 \%$ of patients with choledocholithiasis with an overall complication rate of 5\%.(22) Perhaps the number of patients undergoing CBD exploration in our setting should only be a fraction of the cases if ERCP is routinely available. Across Nigeria, only a few centers perform the procedure on an irregular basis, these being commonly during exhibitions and workshops with invited foreign facilitators.(23) We are gladly aware of ongoing efforts at domesticating the procedure in many centers in Nigeria including ours. We now have trained personnel and have acquired some facilities to kick start the program with some initial proctoring. We are very hopeful that this will be incorporated into our practice very soon. As we are now performing more advanced laparoscopic techniques in our center, acquisition of a choledochoscope in the near future may also enable us perform laparoscopic CBD exploration for the cases with failed ERCP extraction.

The inherent limitations of a retrospective study are not lacking in this study. We have strongly relied on the 
documentation of patient characteristics and findings by the attending surgeons. In a number of instances, desirable records such as number and location of stones were not available thereby limiting our analysis of such data. We are however hopeful that the introduction of electronic data record in our institution will improve documentation and improve similar review in the future. The small number of patients in this review will also limit statistical comparison between the different operative approaches among the patients. A significant limitation in the procedure we employed for CBDE was not routinely deploying fluoroscopy. This may perhaps be useful in reducing occurrence of retained stones like we had in this series.

\section{Conclusion}

This review has shown increasing number of patients undergoing common bile duct exploration similar to the rising cases of gallstones and cholecystectomy in our hospital. We are increasingly adopting primary closure following exploration of the CBD. We are of the opinion that routine availability of ERCP will improve our current management of choledocholithiasis and strongly recommend concerted efforts to increase access to it in our region.

\section{References}

1. Ibitoye $\mathrm{BO}$, Adisa $\mathrm{AO}$, Makinde $\mathrm{ON}$, et al. Prevalence and Complications of Gallstone Disease Among Pregnant Women in a Nigerian Hospital. Int J Gynaecol Obstet. 2014;125(1):41-3

2. Agunloye AM, Adebakin AM, Adeleye JO, et al. Ultrasound Prevalence of Gallstone Disease In Diabetic Patients At Ibadan, Nigeria. Niger J Clin Pract 2013;16(1):71-5

3. Durosinmi MA, Ogunseyinde AO, Olatunji PO, et al. Prevalence af Cholelithiasis in Nigerians With Sickle Cell Disease. Afr J Med Med Sci 1989; 18(3):223-27.

4. Lawal D, Oluwole S, Makanjuola D, et al. Diagnosis, Management and Prognosis Of Obstructive Jaundice In Ile-Ife, Nigeria. West Afr J Med 1998;17(4):255-60

5. Rahman GA, Yusuf IF, Faniyi AO, et al. Management of Patients With Obstructive Jaundice:
Experience In A Developing Country. Nig Q J Hosp Med 2011;21(1):75-9

6. Costi R, Gnocchi A, Di Mario F, et al. Diagnosis And Management of Choledocholithiasis in The Golden Era Of Imaging, Endoscopy And Laparoscopy. World J Gastroenterol 2014;20(37):13382-13401

7. Martin DJ, Vernon DR, Toouli J. Surgical Versus Endoscopic Treatment Of Bile Duct Stones. Cochrane Database Syst Rev 2006; CD003327

8. Bansal VK, Misra MC, Rajan K, et al. Single-Stage Laparoscopic Bile Duct Exploration and Cholecystectomy Versus Two-Stage Endoscopic Stone Extraction Followed by Laparoscopic Cholecystectomy For Patients With Concomitant Gallbladder Stones and Common Bile Duct Stones: A Randomized Controlled Trial. Surg Endosc 2014;28(3):875-85.

9. Papalezova K, Clary B. Stones In The Bile Duct: Clinical Features and Open Surgical Approaches And Techniques. In: Jarnagin WR Ed. Blumgart's Surgery of The Liver, Biliary Tract and Pancreas 5th Edition 2012, Elsevier Saunders, Philadelphia USA

10. Adisa AO, Lawal OO, Arowolo OA, et al. Laparoscopic Cholecystectomy In Ile-Ife, Nigeria. Afr J Med Med Sci 2011;40(3):221-4

11. Wills K, Gibson K, Karihaloot C, et al. Complications Of Biliary T-Tubes After Choledochotomy. ANZ J Surg 2002;72(3):177-80

12. Zhu QD, Tao CL, Zhou MT, et al. Primary Closure Versus T-Tube Drainage After Common Bile Duct Exploration for Choledocholithiasis. Lagenbecks Arch Surg 2011;396:53-62

13. Ambreen M, Shaikh AR, Jamal A, et al.. Primary Closure Versus T-Tube Drainage After Open Choledochotomy. Asian J Surg 2009;32(1):21-5

14. Lee W, Kwon J. Ten-Year Experience on Common Bile Duct Exploration Without T-Tube Insertion. Korean J Hepatobiliary Pancreat Surg 2013;17(2):70-4

15. Gurusamy KS, Samraj K. Primary Closure Versus T-Tube Drainage After Open Common Bile Duct Exploration. Cochrane Database Syst Rev 2007;24(1):CD005640

16. Gurusamy KS, Koti R, Davidson BR. T-Tube Drainage Versus Primary Closure After Open 
Common Bile Duct Exploration. Cochrane Database Syst Rev 2013;21(6):CD005640

17. Leida Z, Ping B, Shuguang W, et al. A Randomized Comparison of Primary Closure and T-Tube Drainage of the Common Bile Duct After Laparoscopic Choledochotomy. Surg Endosc 2008;22(7):1595-600

18. Yin Z, Xu K, Sun J, et al. Is The End of The T-Tube Drainage Era in Laparoscopic Choledochotomy For Common Bile Duct Stones Is Coming? A Systematic Review And Meta-Analysis. Ann Surg 2013;257(1):54-66

19. Podda M, Polignano FM, Luhmann A, et al. Systematic Review With Meta-Analysis Of Studies Comparing Primary Duct Closure and T-Tube Drainage After Laparoscopic Common Bile Duct Exploration For Choledocholithiasis. Surg Endosc 2016;30(3):845-61

20. De Castro VL, Moura EG, Chaves DM, et al. Endoscopic Ultrasound Versus Magnetic Resonance Cholangiopancreatography in Suspected Choledocholithiasis: A systematic review. Endosc Ultrasound. 2016;5(2):118-28

21. Hekimoglu K, Ustundag Y, Dusak A, et al. MRCP Versus ERCP In The Evaluation of Biliary Pathologies: Review of Current Literature. J Dig Dis 2008;9(3):162-9

22. ASGE Standards OfPractice Committee. The Role of ERCP In Benign Diseases of The Biliary Tract. GastrointestEndosc 2015;81(4):795-803

23. Perl D, Leddin D, Bizos D, et al. Endoscopic Capacity in West Africa. Afr Health Sci. 2016;16(1):329-38 